\title{
RI - Ferramentas proteômicas na identificação de novos alvos antigênicos na proteína $M$ do Histoplasma capsulatum e apli- cação em ensaios imunoenzimáticos
}

\author{
Claudia Vera Pizzini ${ }^{1}$
}

\section{1 - Fiocruz}

\section{Introdução:}

A histoplasmose é uma infecção que apresenta amplo espectro clínico, variando desde forma leves, a graves e disseminadas. O diagnóstico da histoplasmose baseia-se nos aspectos clínicos, radiológicos e epidemiológicos. A confirmação se dá pelo isolamento e identificação do Histoplasma capsulatum através de procedimentos microbiológicos. Diferentes metodologias já foram descritas no diagnóstico sorológico da histoplasmose, porém limitações relacionadas a reações cruzadas e limiar de detecção das técnicas empregadas podem dificultar o diagnóstico. $\mathrm{O}$ antígeno $\mathrm{M}$ obtido do extrato antigênico histoplasmina é considerado um antígeno imunodominante para produção de anticorpos, sendo reconhecido em cerca de $90 \%$ dos soros dos pacientes com histoplasmose. O nosso grupo vem trabalhando a vários anos em estudos para um melhor conhecimento desta molécula e aplicação no diagnóstico. Um Modelo molecular do antigeno $M$ foi desenvolvido através de sua sequência, tendo então confirmada sua natureza biológica como catalase. Observa-se também que esta molécula apresentava regiões comuns bem como especificas quando comparadas a catalases de organismos eucariotas.

\section{Objetivo:}

No presente estudo procuramos determinar a presença de possíveis epitopos antigênicos na proteína $M$ empregando ferramentas proteômicas, para posterior emprego em ensaios imunoenzimáticos

\section{Metodologia:}

Foi utilizada a combinação da técnica de coimunoprecipitação com espectometria de massas e posteriormente a técnica de Spot synthesis.

\section{Resultados:}

Com o emprego do anticorpo monoclonal (mAb 1A7) produzido contra a proteína $\mathrm{M}$ recombinante foi possível detectar uma sequência que foi comum às 
duas metodologias empregadas (PTKIIPEELVPFTP). Esta sequência encontra-se localizada numa região onde estudos anteriores, por análise in silico, apontaram como a região mais antigênica desta molécula.

\section{Conclusão:}

Nossa proposta é realizar a síntese desta sequência com diferentes desenhos: extensão de resíduos de lisina e adição da molécula de biotina em ambas as extremidades, carboxi e amino terminal; a síntese da sequência sem adição de outras moléculas, para e posteriore análise em ensaios imunoenzimáticos frente a soros de pacientes com histoplasmose com outras infecções fúngicas, pacientes com tuberculose e frente a indivíduos higidos.

Palavras-Chave: Histoplasmose, diagnóstico com ferramentas proteômicas, imunoensaios 